\title{
KONSEP TAMAN PEKARANGAN SEBAGAI ZONA TERAPI DAN EDUKASI BAGI ANAK AUTIS (STUDI KASUS : SEKOLAH LUAR BIASA (SLB) SUMBER DHARMA MALANG)
}

\author{
The Garden Concept as Therapy \\ and Education Zone for Autism \\ (Case Study : SLB Sumber \\ Dharma Malang
}

\begin{abstract}
Irawan Setyabudi
Staf Pengajar Universitas

Tribhuwana Tunggadewi

Email: isetyabudi.st@gmail.com
\end{abstract}

Wahidyanti Rahayu
Hastutiningtyas
Staf Pengajar Universitas
Tribhuwana Tunggadewi

\begin{abstract}
Open space has potential for development of soft and hard elements and to be around the building can be called a yard. Sometimes, open space only as a building complement if the arrangement is only modest. Planning needs to consider its aspects of accessibility that are friendly to normal people and with special needs. If the environment park is usually still general, such as the use of ramp or handrail, then the focus of the study is on the specific buildings for children with mental and autism in the school extraordinary. Children with autism who have sensory system disorders, fail in responding and not adaptive to the environment, it is necessary a park that has the potential as a means of therapy and education. As a therapeutic means, the garden space organization presents a stimulus for visual, auditory, touch, smell, and taste. The park also serves as a physical, creative, and social play area as education. The selected object as a case study is SLB Sumber Dharma Malang, whose condition is still in the form of ordinary yard and rarely involving students for learning activities outside the classroom. The method of research is qualitative, while the analytical method refers from the thinking of Gold and Hakim, that is architecture design with stage inventory, synthesis-analysis, programing, this research is limited to concept. The inventory stage, the data is taken with photos, sketches, interviews and site measurements, while the analysis phase focuses on the description of potential location and user needs. The aim of the study was to find the concept of garden design as a zone of therapy and education for autistic students. The conclusion is the utilization of SLB open space in accordance with the needs, can help the development of students through sensory stimuli. final output of the study is a site plan including spatial, circulation, activities and facilities plans.
\end{abstract}

Keywords: Garden concept, therapy and education, autism, and yard.

\section{PENDAHULUAN}

Saat ini perkembangan ruang terbuka sedang digiatkan untuk membentuk ruang terbuka hijau, seperti program pemerintah kampung tematik, kampung bersinar, green and clean, dan sebagainya, agar ruang terbuka menjadi lebih bermakna. Ruang terbuka hijau (RTH) adalah area tempat tumbuh tanaman baik yang tumbuh secara alami ataupun sengaja ditanam. Aspek pemanfaatan RTH sekitar bangunan (lingkup mikro) sebagai taman, dapat dinikmati secara visual dan memberikan suasana teduh. Hal ini berhubungan dengan fungsi rekreatif. Taman juga memiliki variasi fungsi lainnya seperti ketahanan pangan mandiri (urban farming) melalui vertikultur, selain itu untuk fungsi estetika, edukasi dan healing (sarana terapi suatu penyakit).

Pemanfaatan ruang terbuka yang berada pada sekeliling bangunan atau bisa disebut pekarangan, yang disebutkan pada Peraturan Menteri Pekerjaan Umum No : 05/PRT/M/2008 adalah lahan di luar bangunan yang berfungsi untuk aktivitas. Lahan sisa yang berada di sekitar bangunan termasuk pekarangan baik dalam skala kecil ataupun besar. Rancangan RTH biasanya hanya disesuaikan bagi orang berkebutuhan normal, hanya pada titik tertentu yang dirancang untuk berkebutuhan khusus, seperti penggunaan ramp pada sirkulasi dan pemakaian ubin kasar sebagai penanda bagi tuna netra.
Penggunaan lahan pekarangan untuk taman berkebutuhan khusus tidak sesederhana demikian. Bagi difabel atau different ability; yang dibedakan menjadi cacat fisik dan mental; terdapat perlakuan khusus pada rancangan taman. Fokus kajian pada penelitian ini, pada olah tata ruang taman pada bangunan sekolah luar biasa untuk autis. Alasannya, belum adanya suatu konsep yang membahas taman untuk siswa autis secara spesifik. Sebelumnya, autis dapat didefinisikan oleh Haliimah, et al (2014), sebagai kelainan karakter dengan gejala yang tampak adalah ketidakpedulian terhadap lingkungan sekitar, seperti menolak berinteraksi sehingga merasa hidup dalam dunianya sendiri. Anak yang mengidap autisme terkadang sulit untuk berkomunikasi secara verbal dan ada kecenderungan kelainan pada persepsi sensorisnya. Peran ruang terbuka sebagai taman untuk sarana belajar, bermain, dan sarana terapi diperlukan untuk siswa autis.

Pengaruh ruang luar sebagai taman edukasi terhadap perkembangan anak disampaikan oleh beberapa ahli, seperti disebutkan oleh Ramadhani (2016), bahwa salah satu bentuk pembelajaran adalah memberikan pengalaman langsung, sehingga siswa lebih mudah memahami. Contohnya adalah saat mata pelajaran IPA, siswa secara langsung dapat memahami karakter tanaman yang tumbuh di taman. Aspek ini, taman berfungsi sebagai edukasi. Lauren (2012), menyebutkan bahwa ruang terbuka seringkali digunakan sebagai 
taman bermain anak dengan fasilitas pendukungnya. Aktivitas tersebut termasuk edukatif, yang mana usia anak yang masih muda dapat peka terhadap rangsangan dari lingkungannya. Baskara (2011) dalam penelitiannya juga membahas tentang taman untuk edukasi anak-anak, mampu untuk membangkitkan sisi kognitif, sosial, fisik, serta kemampuan emosi yang diperlukan saat dewasa. Penyediaan fasilitas tentu harus dipertimbangkan pada sisi keamanan dan keselamatannya, seperti penggunaan material yang tidak berbahaya atau vegetasi yang tidak beracun.

Sebagai sarana terapi untuk siswa autis, taman harus memberikan suatu manfaat perubahan. Taman dikembangkan dengan konsep sensori atau berhubungan dengan panca indera. Adapun Haliimah (2014), menyebutkan bahwa sistem sensori dalam tubuh ada vestibular (gerakan keseimbangan), proprioceptive (otot-motorik), visual (penglihatan), auditory (pendengaran), tactile (peraba), gustatory (pengecap), dan olfactory (penciuman). Menurut Prabowo (2015), unsur yang paling kuat memiliki pengaruh adalah bunyi. Konsep taman terapi sensorik untuk autis oleh Wahyuni (2015) dibedakan menjadi dua yaitu untuk hipersensistif dan hiposensitif. Taman terapi hipersensitif dengan konsep melingkar untuk mengontrol anak yang selalu aktif bergerak. Elemen vegetasi yang digunakan bertekstur halus seperti sutra bombay, dan air berirama rendah untuk efek menenangkan. Sedangkan, hiposensitif berbentuk tegas dan cukup luas untuk bergerak. Elemen vegetasi dengan tekstur jelas yaitu asparagus dan bunga balon. Fitur air yang digunakan berundak, untuk menstimulus lebih aktif.

Data primer yang diperoleh pada penelitian ini digunakan dengan foto-foto, wawancara, sketsa dan pengukuran lokasi yang diperoleh saat proses inventarisasi. Adapun data sekunder didukung dari internet mengenai profil sekolah ataupun akses dengan google maps. Permasalahannya adalah bagaimana konsep taman sensorik sebagai zona terapi dan edukasi bagi siswa penderita autis? Studi kasus adalah Sekolah Luar Biasa (SLB) Sumber Dharma Malang, alasannya adalah lokasi berada dalam kota jauh dari pusat keramaian dengan suasana tenang, berpotensi untuk dikembangkan taman dengan konsep baru karena taman sebelumnya hanya terdapat penataan pot dan area bermain anak.

\section{METODE}

Penelitian dilakukan dengan metode kualitatif dengan cara deskripsi deduktif dan induktif. Nasution (2004) menyebutkan bahwa penelitian deskriptif adalah penelitian yang memberikan penjelasan tentang gambaran situasi. Metode pengolahan data dengan desain arsitektur yaitu berasal dari pemikiran Gold dan Hakim. Teori dari Gold (1980) disebutkan bahwa rancangan taman terdiri atas persiapan, analisis, sintesis, konsep pengembangan dan perencanaan. Hakim (2012) juga menyebutkan bahwa proses diawali dengan penetapan proyek, inventarisasi, programatik ruang (tahap analisis-sintesis pada tapak dan pengguna), konsep, pradesain hingga pengembangan desain. Dalam artikel ini dibatasi hingga konsep untuk rekomendasi desain.

Penelitian ini diawali dari studi inventarisasi atau pendataan unsur hardscape dan softscape sebagai data primernya, berupa wawancara, foto, sketsa dan rekaman. Berikutnya analisis-sintesis potensi dan kendala lokasi fisik penelitian serta penentuan kebutuhan pengguna, hingga melahirkan konsep. Hasil penelitian ini lebih pada konsep pengembangan ruang sebagai penelitian pendahuluan pada SLB Sumber Dharma Malang. Wujud hasil analisis ini adalah sketsa konsep dan aplikasi komponen desain sebagai tahap awal dari desain. Rekomendasi desain tersebut berupa gambar block plan dan uraian deskriptif tentang rancangan taman sensorik.

Menurut Haliimah, et al (2014), penderita autis adalah penderita gangguan pengolahan informasi sensoris akibat kelainan pada sistem sarafnya. Jika orang normal, sistem saraf pusat memproses segala informasi yang datang dari kelima indera, maka penderita autis mengalami gangguan informasi sensoris sehingga tidak dapat beradaptasi terhadap lingkungannya. Adapun kriteria desain taman dengan konsep sensory garden antara lain sebagai berikut :

a. Tata massa, ada aktivitas visual ke luar tapak untuk mengawasi aktivitas anak dan ruang luar tenang namun tidak menutup diri

b. Material, menggunakan material perkerasan yang tidak licin, menyerap air dan tidak membahayakan, serta memilih tanaman yang tidak beracun, tidak berduri dan aman dikonsumsi, serta adanya unsur softscape dan hardscape yang merangsang anak hiposensitif dan menenangkan anak hipersensitif.

c. Aksesbilitas, jalan tidak membingungkan dan mudah menemukan kembali jalan pulang

d. Zonasi, pemisahan antara zona anak hiposensitif dan hipersensitif, tersedia taman untuk terapi, rekreasi dan relaksasi, adanya tempat yang tenang untuk mencegah stres, menyediakan tempat untuk interaksi, dan pengalaman sensori

e. Kelengkapan taman, tersedia taman yang melatih motorik, keseimbangan dan koordinasi, dan adanya fitur air yang menstimulasi pendengaran, peraba, serta menenangkan 
Kriteria taman dengan konsep sensory garden sebagai terapi anak autis dijelaskan juga oleh Prabowo (2015) berkaitan tentang pemilihan objek taman untuk terapi panca indera :

a. Indera pengecap, beberapa tanaman memiliki buah yang langsung bisa dinikmati dan merangsang indera pengecap yaitu jeruk, tomat, dan belimbing

b. Indera penglihatan, penggunaan warna pastel (warna muda) yang diperoleh dari penambahan warna putih terhadap warna dasar, membuat warna tidak mengintimidasi, yang digunakan pada unsur hardscape

c. Indera penciuman, adanya tanaman yang beraroma wangi seperti lavender, alyssum, lily, rose, kacapiring

d. Indera peraba, penggunaan material berbeda tekstur pada alur sirkulasi taman

e. Indera pendengaran, menyediakan area burung berkicau, seperti lovebird dan blackthroat.

Taman sensorik untuk siswa SLB juga termasuk dalam taman edukasi. Menurut Mandagi (2013) kriteria taman edukasi sebagai berikut.

a. Adanya ruang edukasi, yang terdiri atas area observasi untuk memberikan edukasi mengenai ragam jenis vegetasi maupun satwa kepada anak-anak. Area ini termasuk kegiatan pasif karena pengunjung hanya berjalan dan mengamati.

b. Penggunaan elemen keras dan lunak. Elemen keras pada anak-anak menggunakan material dari alam atau menyerupai alam, seperti kayu dan batu-batuan. Adaptasi dari alam menciptakan kesan alami dan selaras dengan lingkungan. Utamanya pemilihan material tidak beracun dan aman bagi anak-anak. Elemen lunak digunakan tanaman berdasarkan fungsi vegetasi, baik sebagai peneduh, pembatas ataupun estetis. Vegetasi peneduh bertajuk payung seperti ketapang, pembatas contohnya semak penitian, sedangkan estetis seperti tanaman berbunga atau berdaun indah.

c. Adanya ruang bermain. Ada permainan yang diakomodasi dalam suatu taman yaitu permainan fisik, kreatif, sosial, indera dan ketenangan. Tipe permainan ini bersifat edukatif karena mengajarkan anak supaya berkembang, seperti halnya permainan fisik yang menuntut selalu aktif merangsang motorik; taman kreatif yang merangsang daya imajinasi; taman sosial yang merangsang anak-anak beradaptasi dengan teman sebayanya menurut mereka sendiri; taman indera yang menstimulasi indera peraba, pendengaran, penglihatan, penciuman dan memperkaya pengalaman; serta permainan ketenangan yang menyediakan area untuk istirahat yang bersifat menenangkan.

Adapun kriteria pemilihan vegetasi RTH taman pekarangan menurut Peraturan Menteri Pekerjaan Umum No : 05/PRT/M/2008 sebagai berikut, (a) Memiliki estetika yang menonjol, (b) sistem perakaran yang masuk ke dalam tanah, tidak merusak konstruksi bangunan, (c) tidak beracun, tidak berduri, dahan tidak mudah patah, (d) ketinggian taman bervariasi, warna hijau dengan kombinasi seimbang warna lain, (e) jenis tanaman tahunan atau musiman, (f) tahan terhadap hama penyakit tanaman, (g) mampu menyerap cemaran udara, (h) sedapat mungkin merupakan tanaman yang mengundang burung.

\section{HASIL DAN PEMBAHASAN}

\section{Kondisi Eksisting Studi Kasus}

Studi kasus SLB Sumber Dharma berada di Jalan Jago Malang, yang tidak jauh dari Masjid Sabilillah dan jalan arah ke Surabaya. (Gambar 1). Sekolah dikelilingi oleh permukiman warga dan aksesnya masuk pada gang dengan lebar jalan 4 meter. Bangunan sekolah terdiri atas 2 lantai yang memiliki ruang terbuka yang terbatas. Luas total tanah adalah $576 \mathrm{~m}^{2}$ yang terbagi atas luas bangunan dan taman. Taman pada sekolah ada pada taman depan dan tengah. Taman depan dengan panjang 17 meter dan lebar 4 meter, atau $62 \mathrm{~m}^{2}$ setelah dikurangi luas teras, sedangkan taman tengah memiliki dimensi panjang 14 meter dan lebar 4 meter atau luasannya 56 m2. Sebuah luasan taman yang cukup sempit jika ada pembagian zona tertentu taman. (Gambar 2). Menurut data pokok sekolah, SDM terdiri atas guru 6 orang dan siswa dengan total 26 anak yang terbagi atas TKLB, SDLB, SMPLB, dan SMALB. Ruangan yang tersedia ada 7 ruang kelas dan tidak ada laboratorium maupun ruang perpustakaan.

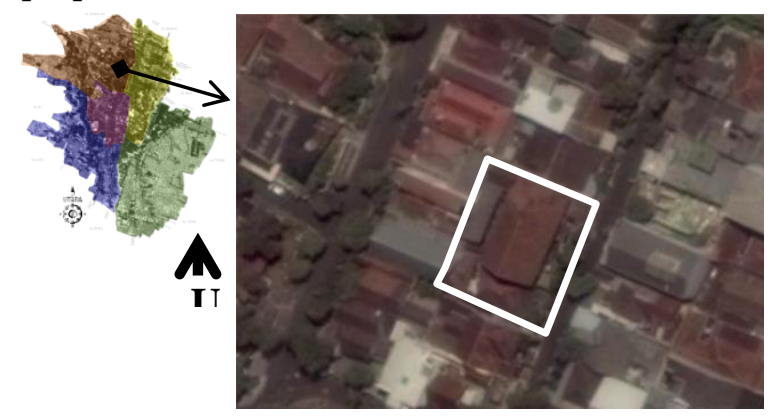

Gambar 1. Lokasi SLB Sumber Dharma Malang di Kecamatan Lowokwaru 
Menurut pengamatan (Gambar 2), taman depan digunakan sebagai area parkir sepeda, area bermain, berkebun dan tempat duduk bagi orang tua yang akan menjemput anak. Tanaman yang ada sudah cukup bervariasi mulai tanaman hias, tanaman dengan rak, pohon peneduh, sampai pada taman model vertikultur sederhana. Pada lahan eksisting taman depan terdapat puring, drasena, kamboja, kopi, lidah buaya, manisa, sawo, buah naga, sansivera, pucuk merah, kuping gajah, palem, temulawak, lamtoro, kol banda, jeruk, jambu, cabe, lili paris dan blimbing. Penataan taman masih belum dikelompokkan sehingga masih terlihat seperti pekarangan yang belum rapi. Adapun program sebelumnya juga ada yang melibatkan siswa yaitu vertigarden ceria yang merupakan proyek PKM mahasiswa tahun 2014 untuk membuat vertikultur, namun keberlanjutannya tidak ada sehingga pot terbengkalai. Bukan tanpa alasan, hanya guru yang merawat taman di sekolah ini. (Gambar 4).

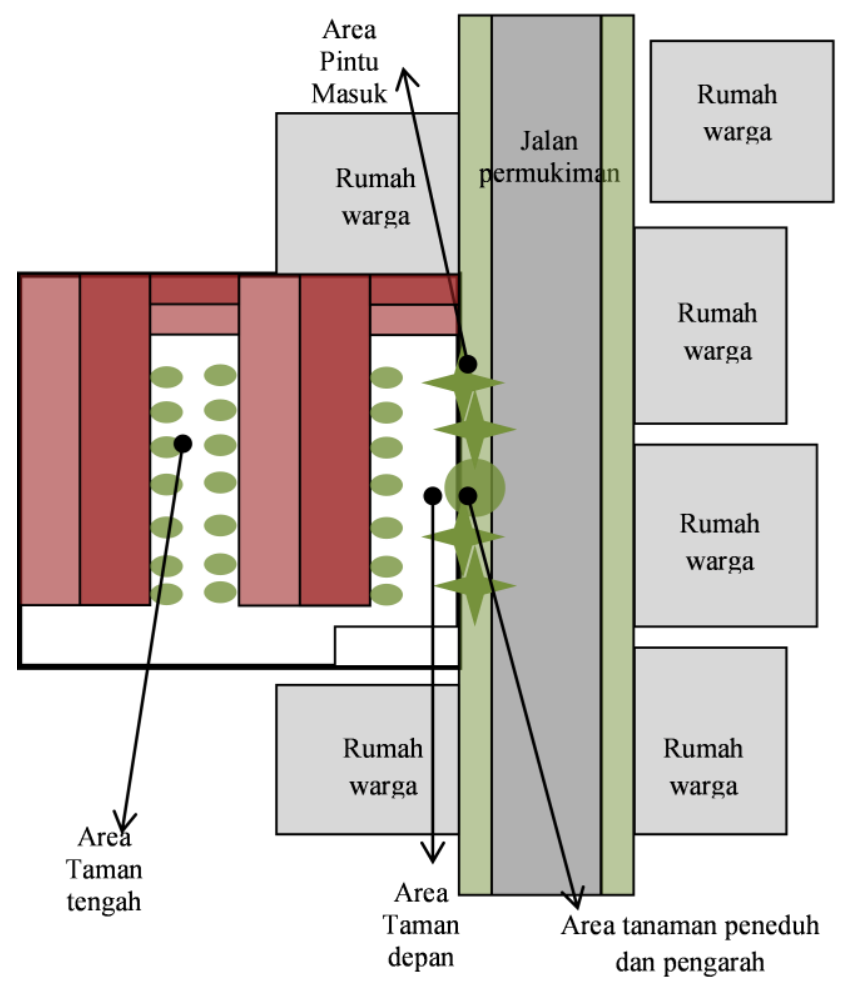

Gambar 2. Ilustrasi lokasi taman SLB Sumber Dharma Malang berikut area sekelilingnya

Taman tengah berbeda fungsi dengan taman yang ada di depan. Taman tengah untuk upacara siswa sehingga lebih dibutuhkan area bebas, dan terdapat tanaman dalam rak di depan musholla dan ruang kelas. Adapun vegetasi eksisting adalah puring, kamboja, adam hawa, kol banda, temulawak, terong, beras kutah, sansivera, drasena, dan suruh. Ada hal yang menarik di taman tengah, siswa mulai menerapkan barang reuse berupa botol air mineral untuk pot, dengan model seperti hanging garden. Pengembangan taman yang dimungkinkan adalah ke arah vertikal. Penataan pada taman depan dan tengah masih belum terkelompokkan dan fungsi tanamannya rata-rata adalah tanaman hias, yang kurang berdampak pada siswa. (gambar 5).

\section{Aspek Tapak}

Menurut Gold (1980) ataupun Hakim (2012), setelah proses inventarisasi atau pendataan tapak adalah programming yang berkaitan dengan analisis tapak dan pengguna. Secara aksesbilitas, taman depan mudah dicapai dari luar pagar untuk menuju ke gedung atau taman tengah melalui jalan samping. Orang tua siswa biasanya duduk-duduk sambil menunggu jam istirahat atau pulang. Taman depan jarang diakses oleh siswa karena setelah datang langsung menuju ruang kelas. Siswa lebih sering mengakses taman tengah karena selain jalan menuju ke ruangan toilet dan mushola juga digunakan untuk lapangan upacara. Aspek sirkulasi, taman depan menyediakan akses loop atau memutar linear sedangkan taman tengah bisa diakses dari berbagai arah. Aspek vegetasi, belum ada pengelompokan taman antara tanaman peneduh, hias, pembatas atau pengarah, sehingga masih terkesan supaya 'hijau' saja. Aspek view atau pandangan dari luar ke dalam tapak, taman tidak terlihat langsung dari luar pagar karena ada tanaman pembatas yang memberikan kesan privat (gambar 3), sedangkan taman tengah dapat dilihat dari lantai 2 dan ruang kelas sekitarnya. Kendala tapak sekaligus tantangan adalah ukuran lahan yang relatif sempit sehingga penataan ruang perlu dimaksimalkan agar aktivitas terapi dan edukasi dapat diakomodasi.

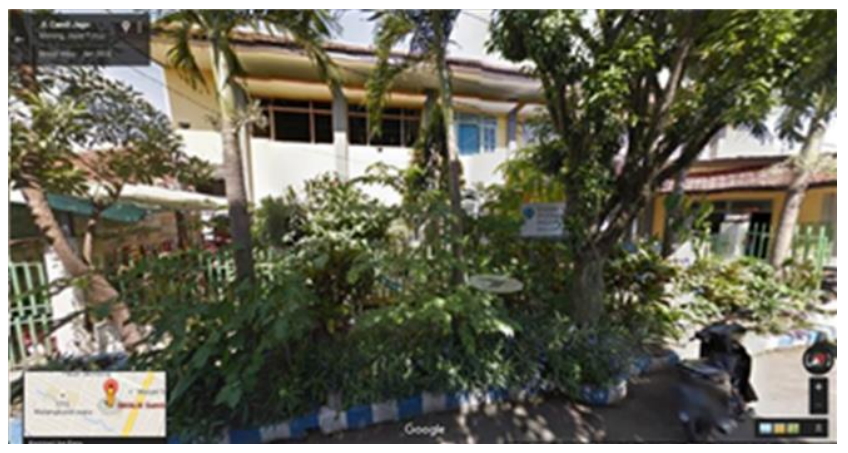

Gambar 3. Ilustrasi foto tampak depan SLB Sumber Dharma dari Google Street View 

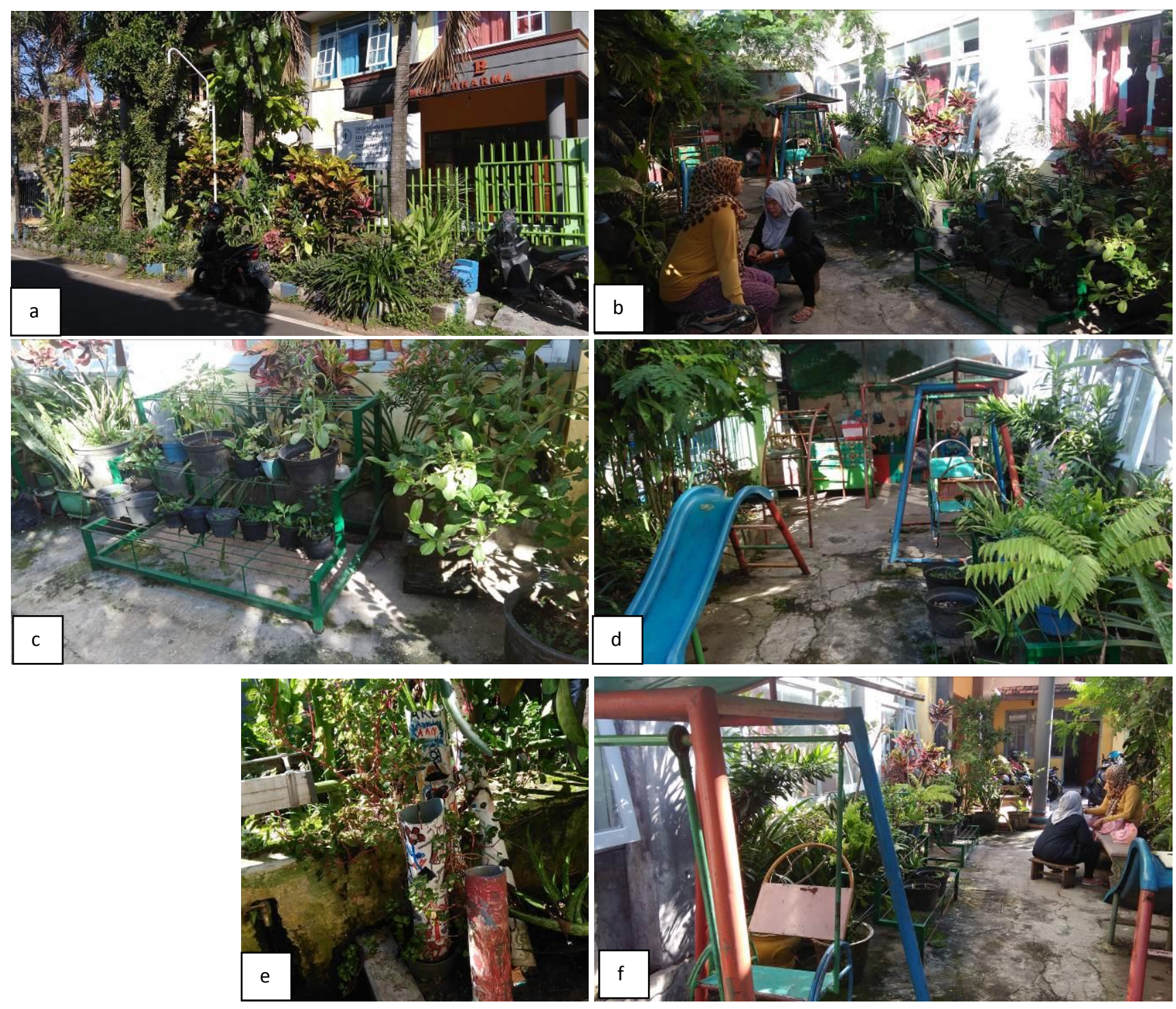

Gambar 4. Kondisi lingkungan taman depan gedung SLB (a) tanaman memenuhi area pagar, (b) area tempat duduk ditempati oleh orang tua yang sedang menjemput, (c) rak tanaman, (d) tempat bermain siswa, (e) keberlanjutan vertikultur pada vertigarden ceria yang masih kurang perawatan, (f) sisi lain area tempat bermain siswa

\section{Aspek Pengguna}

Pengguna tapak terbatas pada guru, siswa, orang tua siswa, dan tamu. Taman depan merupakan area semipublik yang masih bisa diakses oleh orang tua siswa sedangkan taman tengah bersifat privat karena hanya terbatas pada guru dan siswa. Umumnya area taman digunakan pada pagi sampai siang hari pada jam tertentu seperti sebelum masuk, saat istirahat ataupun pulang sekolah. Namun secara umum taman masih kurang difungsikan.

Menurut narasumber salah satu guru yaitu ibu Christina Sri Purwatiningsih (ibu pur) selaku guru SMPLB, taman yang diharapkan adalah bersifat teduh, melibatkan siswa dalam proses penanaman ataupun mata pelajaran yang bertema (Gambar 6), dan prioritas taman depan karena penyinaran maksimal diperoleh pada depan bangunan. Seperti yang diketahui bangunan menghadap ke arah timur yang optimal terhadap penerimaan sinar.

Pengguna utamanya adalah siswa dari berbagai tingkatan kelas dan terbagi atas beberapa tuna, yaitu tuna grahita, tuna rungu dan autis. Tema taman memang ditujukan pada anak autis tetapi juga bisa untuk tuna yang lain karena taman sensorik mampu merangsang panca indera untuk terapi dan edukasi.

\section{Zona Ruang}

Pekarangan sekolah dirancang untuk menunjang aktivitas belajar sekolah di luar ruangan (Outdoor 
Learning Process), sekaligus sebagai sarana terapi okupasi (terapi dengan kesibukan aktivitas). Siswa bisa
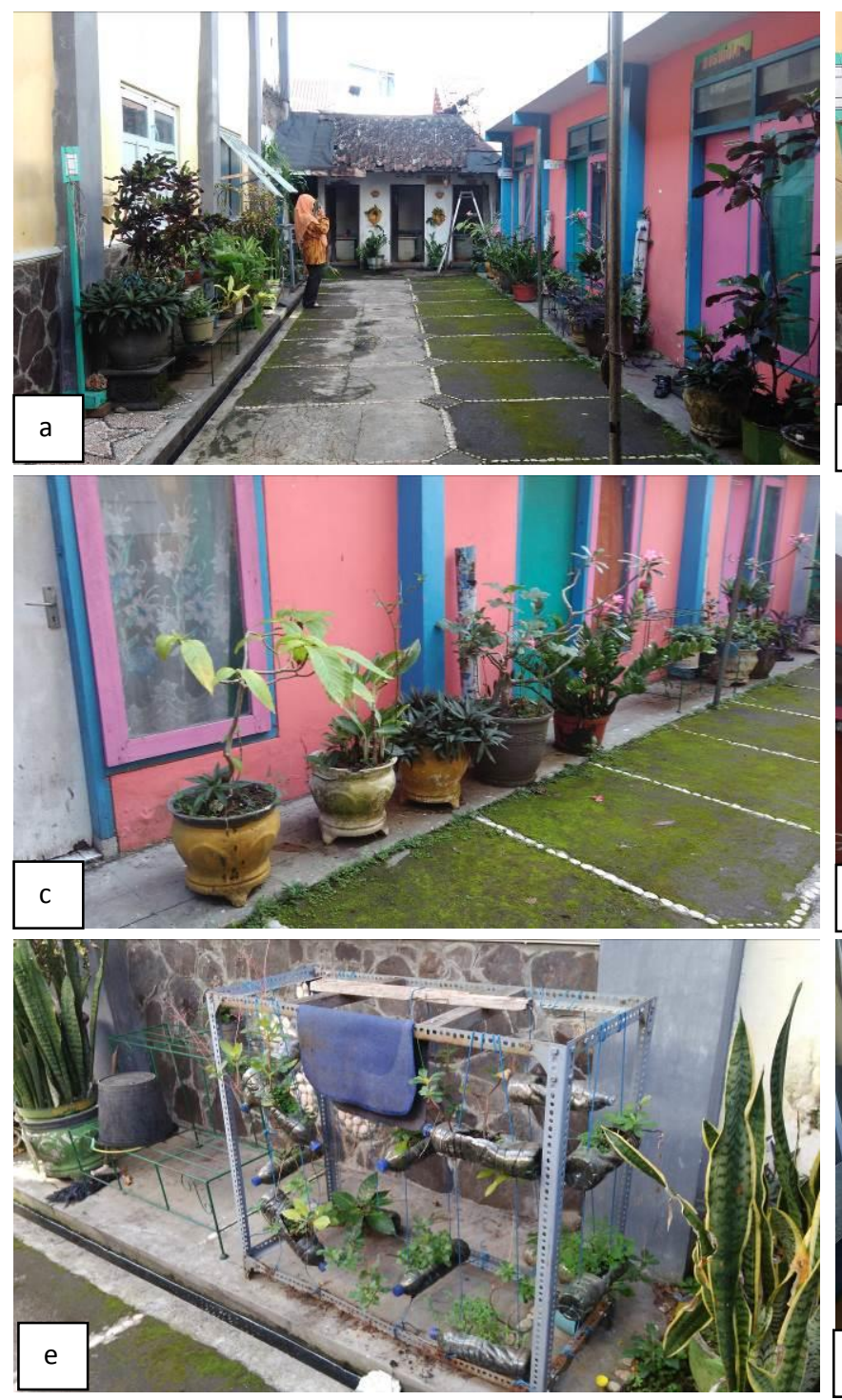

dilibatkan dalam aktivitas menanam sederhana (yang tidak melibatkan senjata tajam seperti cangkul, linggis,
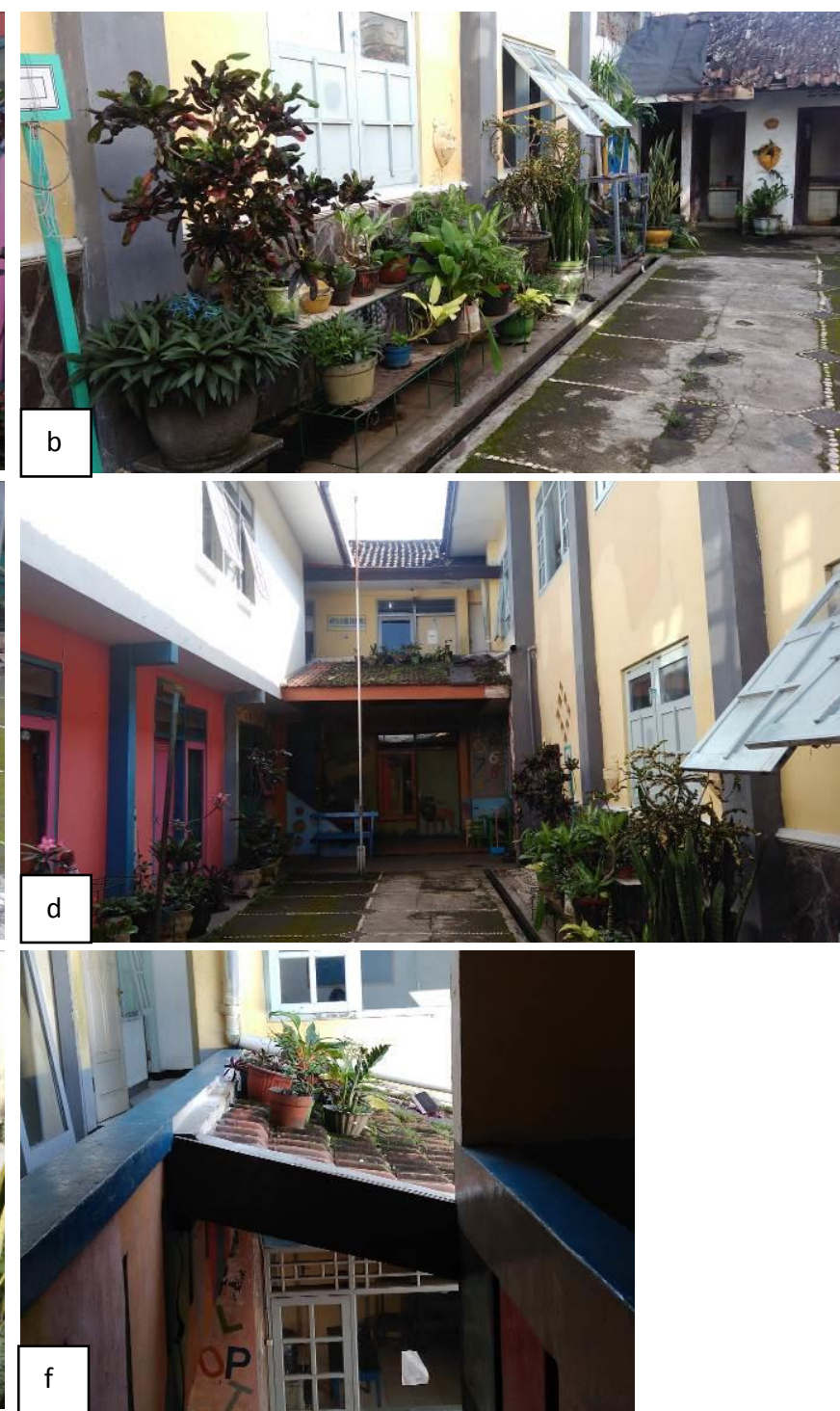

Gambar 5. Kondisi lingkungan taman tengah gedung SLB (a) taman tengah sebagai lapangan upacara dan dibatasi oleh ruang kelas dan mushola, (b) jenis tanaman pada taman tengah, (c) pot-pot yang mengisi ruang di depan ruang kelas, (d) sisi lain dari taman tengah, (e) area vertikultur dengan botol bekas, (f) pot juga mengisi area hijau pada atap

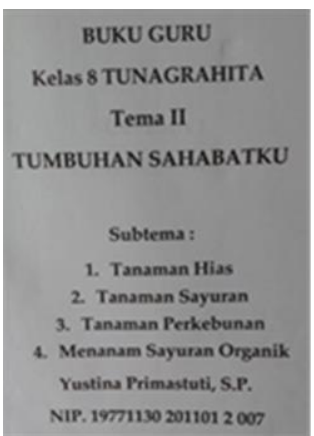

Gambar 6. Contoh buku pegangan guru yang membuktikan pemanfaatan taman untuk kegiatan belajar mengajar arit, dan sebagainya) namun menggunakan peralatan yang aman dengan pengawasan guru. Tanaman yang ditanam bisa hortikultura dalam pot. Model tanam yang sekarang sedang berkembang sebagai antisipasi lahan terbatas adalah penanaman secara bertingkat dengan vertikultur dan susunan pot secara bertingkat. Berdasarkan kriteria taman dengan konsep sensory garden, dihasilkan zona taman seperti pada Gambar 7 dan 8. Perlakuan sedikit berbeda untuk anak autis yang hipersensitif (taman yang menenangkan) dan hiposensitif (taman yang merangsang gerak aktif). Taman ini sebenarnya tidak hanya diakses oleh anak autis saja namun semua warga sekolah. 
Taman depan sekolah bersifat ruang semi publik yang bisa diakses oleh orang luar namun terbatas pada penjemput atau orang tua siswa, terdapat pagar, kantin dan parkir serta taman. Area ini sesuai untuk anak autis dengan hiposensitif, dengan taman bermain aktif. Urutan alur zonasinya dapat diakses secara linear yang dimulai dari (1) area terapi penglihatan (visual), berada di sebalah zona terapi pengecap dan penciuman, dengan menggunakan media tanaman hias warna-warni dan warna pastel cat dengan pola tertentu pada dinding atau perkerasan, (2) area tempat duduk bagi penjemput atau orang tua. (3) area bermain aktif (vestibular), tempat bermain berada di tengah taman dengan ayunan, perosotan, dan panjatan untuk melatih keseimbangan, (4) area terapi pengecap dan penciuman, berada di dekat area tunggu dan sirkulasi menuju ke dalam gedung sekolah, zona ini terdapat tanaman yang merangsang indera pengecap, seperti ada tanaman buah siap petik, sedangkan indera penciuman dengan tanaman aromatik, (5) area terapi peraba (tactile), didapatkan dengan permainan permukaan kasar-halus suatu benda, seperti model paving atau material batu tempel yang berbeda, (6) area terapi pendengaran, disediakan taman burung yang beraneka ragam jenisnya serta penambahan alat musik berupa drum, (7) area meditasi, berada di ujung sebelum kantin, area ini terdapat permainan air mancur, selain merangsang pendengaran juga untuk menenangkan diri. (8) area tanaman vertikal, berada di sebelah dalam dari pagar dan sebelum dinding gedung sekolah, bisa dengan tanaman model rak ataupun vertikultur. Adapun alur hubungan antar ruang pada Gambar 9.

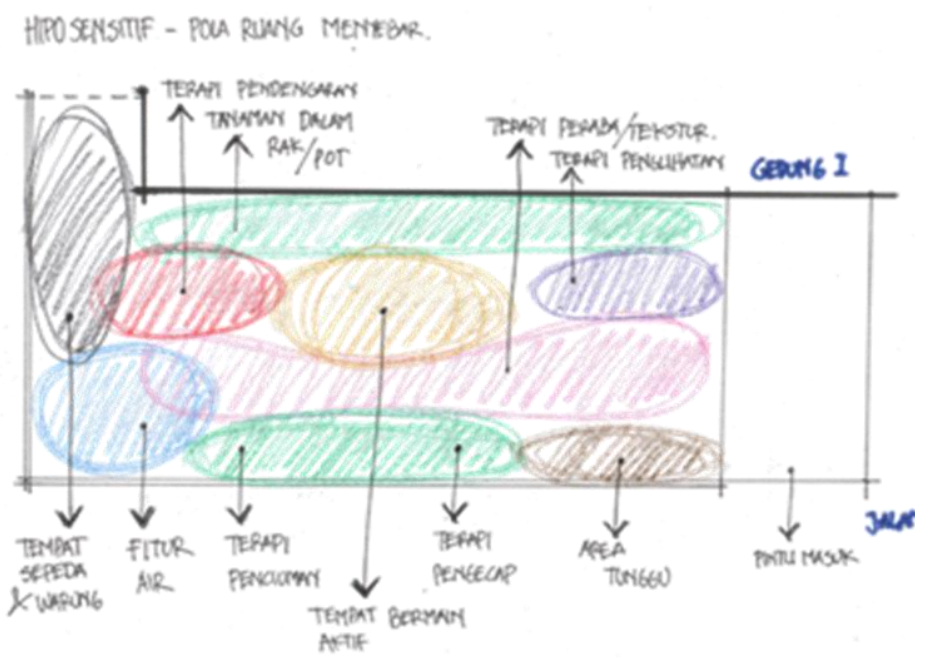

Gambar 7. Zonasi taman depan

Taman yang kedua adalah taman tengah dengan luasan yang sedikit lebih kecil dari sebelumnya, yang ditunjukkan pada Gambar 8. Area taman ini sesuai untuk anak autis yang hipersensitif, yang mencari taman untuk ketenangan. Pembagian zona hampir sama dengan taman pertama namun ditambahkan gazebo dan pohon peneduh. Perlu diketahui bahwa taman kedua ini difungsikan juga sebagai lapangan upacara sehingga area taman cukup terbatas. Dengan tidak merubah kondisi eksisting yang mengkondisikan tanaman pot secara bertingkat, bisa ditambahkan vertical garden dan tanaman gantung untuk memanfaatkan dinding agar tidak terkesan kosong. Perbedaannya yang lainnya adalah pemilihan bahan dan material untuk taman sensorik. Warna tanaman dipilih analogus dari hijau, tekstur perkerasan halus, dan masih menggunakan pola pot dengan rak bertingkat.

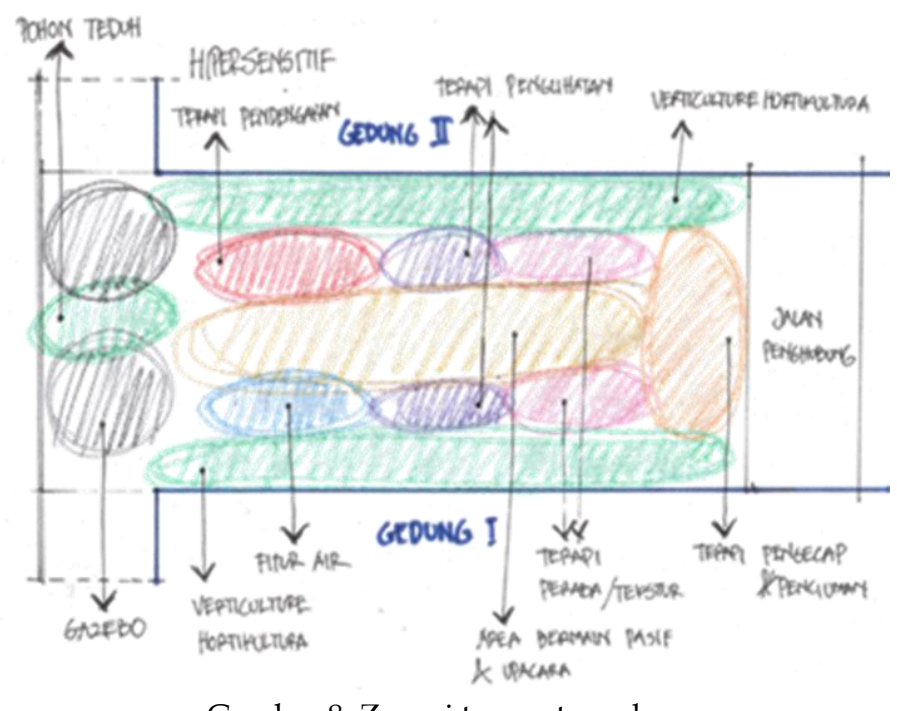

Gambar 8. Zonasi taman tengah

\section{Konsep dasar ruang}

Hasil penelitian ini menyempurnakan dari konsep yang sudah ada sebelumnya, dan kriteria taman sebagai zona terapi dan edukasi diperoleh dengan hasil penelitian di atas. Adapun konsep dasar dalam merancang taman untuk anak autis didapatkan sebagai berikut :

a. Konsep bentuk, pada perkerasan atau sirkulasi ataupun unsur hardscape bisa berbentuk dasar organik untuk hipersensitif dan berbentuk kaku atau bersudut untuk hiposensitif. Bentuk organik seperti melingkar akan memberikan ketenangan, sedangkan bentuk bersudut akan memberikan efek peningkatan konsentrasi.

b. Konsep sirkulasi terdapat terapi keseimbangan (vestibular), pada taman untuk hiposensitif perlu disediakan lahan yang cukup luas untuk untuk memacu bergerak aktif, seperti ruang terbuka dan adanya tempat bermain. Namun kenyataannya lahan sempit sehingga perlu pembagian ruang yang terpenuhi semua aktivitas. Kontur atau tinggi rendah taman harus landai karena anak takut untuk bergerak 
lebih. Berbeda dengan hipersensitif yang melatih bergerak lebih teratur dan pelan sehingga sirkulasi dirancang berundak. Pola ruang sebaiknya memiliki urutan tertentu sehingga diarahkan menuju ke suatu tempat dan dapat merasakan perbedaan tiap zona, hal itu berlaku untuk hiposensitif yang mencari stimulus, berbeda dengan hipersensitif yang lebih baik dengan pola sirkulasi menyebar.

c. Konsep vegetasi, mengikuti konsep pembagian ruang. Seperti area terapi penglihatan dengan tanaman hias warna warni, area terapi pengecap dan penciuman dengan tanaman buah yang siap petik (jeruk, tomat, dan sebagainya) dan ada tanaman aromatik seperti lavender dan melati. Sebagai taman edukasi yang melibatkan siswa untuk bercocok tanam seperti pengenalan jenis tanaman, atau tempat menanam dengan tujuan untuk dipetik sendiri (urban farming), seperti sawi pokcoy dan selada air dengan model vertikultur. Proses penanaman tersebut sebagai penerapan terapi okupasi (aktivitas). Vegetasi juga dikelompokkan menjadi tanaman perdu dan hias, groundcover, tanaman hortikultura, tanaman aromatik, tanaman peneduh, tanaman pembatas, tanaman pengarah seperti pada Tabel 1 .

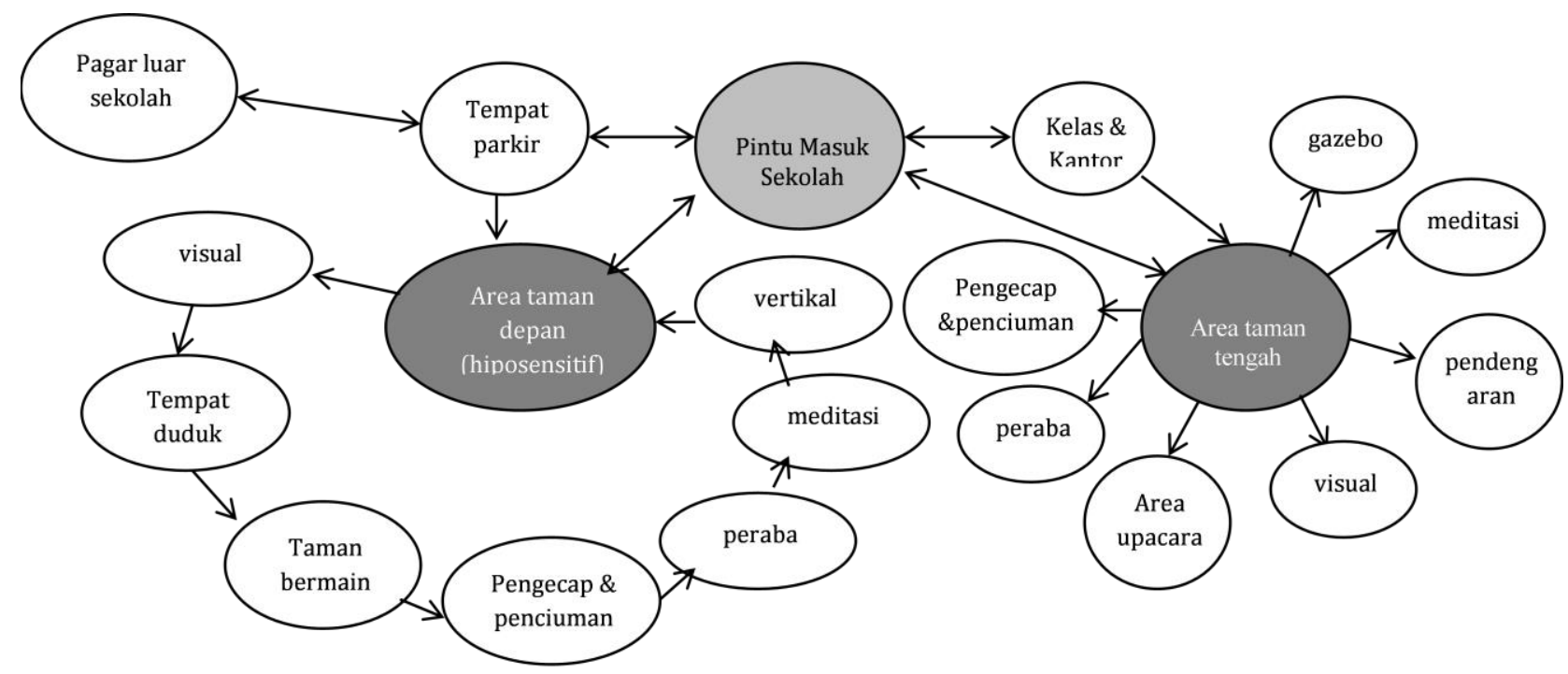

Gambar 9. Diagram bubble untuk hubungan antar ruang

Adapun taman edukasi dan terapi untuk anak autis hasil generalisasi dari uraian konsep yang didapatkan studi di atas untuk menambahkan pendapat dari Mandagi (2013), Haliimah (2014), Wahyuni (2015) dan Prabowo (2015) adalah sebagai berikut,

a. Tata ruang dibagi menjadi 2 kelompok besar yaitu untuk autis hiposensitif dan hipersensif yang jenis ruangnya hampir mirip. Perbedaannya, hiposensitif disediakan ruang untuk melatih keaktifan seperti area bermain aktif (perosotan, ayunan, dan sebagainya) yang dinilai aman seperti pendapat Baskara (2011). Hipersensitif perlu disediakan taman yang menenangkan seperti adanya area teduhan berupa pohon atau gazebo. Alur ruang sebisa mungkin linear dan loop, sehingga mengarahkan siswa menuju ke suatu tempat namun bisa dirasakan semua.

b. Sebagai taman terapi sensorik, area taman dibagi menjadi taman untuk merangsang visual, pengecap, penciuman, peraba dan pendengaran.
Adapun penerapan konsep taman sensorik dapat berpengaruh terhadap perilaku anak siswa yang sebelumnya memiliki dunia sendiri menjadi lebih fokus terhadap sesuatu, seperti warna, rasa, bau, tekstur dan suara. Perilaku lainnya jika siswa terlalu banyak gerak maka akan lebih menenangkan melalui suasana alami.

c. Sebagai taman edukasi, taman sebagai aplikasi mata pelajaran dengan pengenalan jenis tanaman (outdoor learning process) dan disediakan area bercocok tanam untuk belajar merawat, menyiram dan memanen.

d. Urban farming pada pekarangan, dengan adanya isu keterbatasan lahan akhir-akhir ini, siswa dapat diberikan pemahaman agar penanaman tidak hanya diberlakukan secara horizontal. Dengan sistem baru yaitu vertikultur, tanaman dapat dikembangkan secara vertikal dengan pilihan tanaman yang produktif seperti sayuran. 
SETYABUDI, HASTUTININGTYAS

Tabel 1. Rekomendasi nama dan jenis tanaman

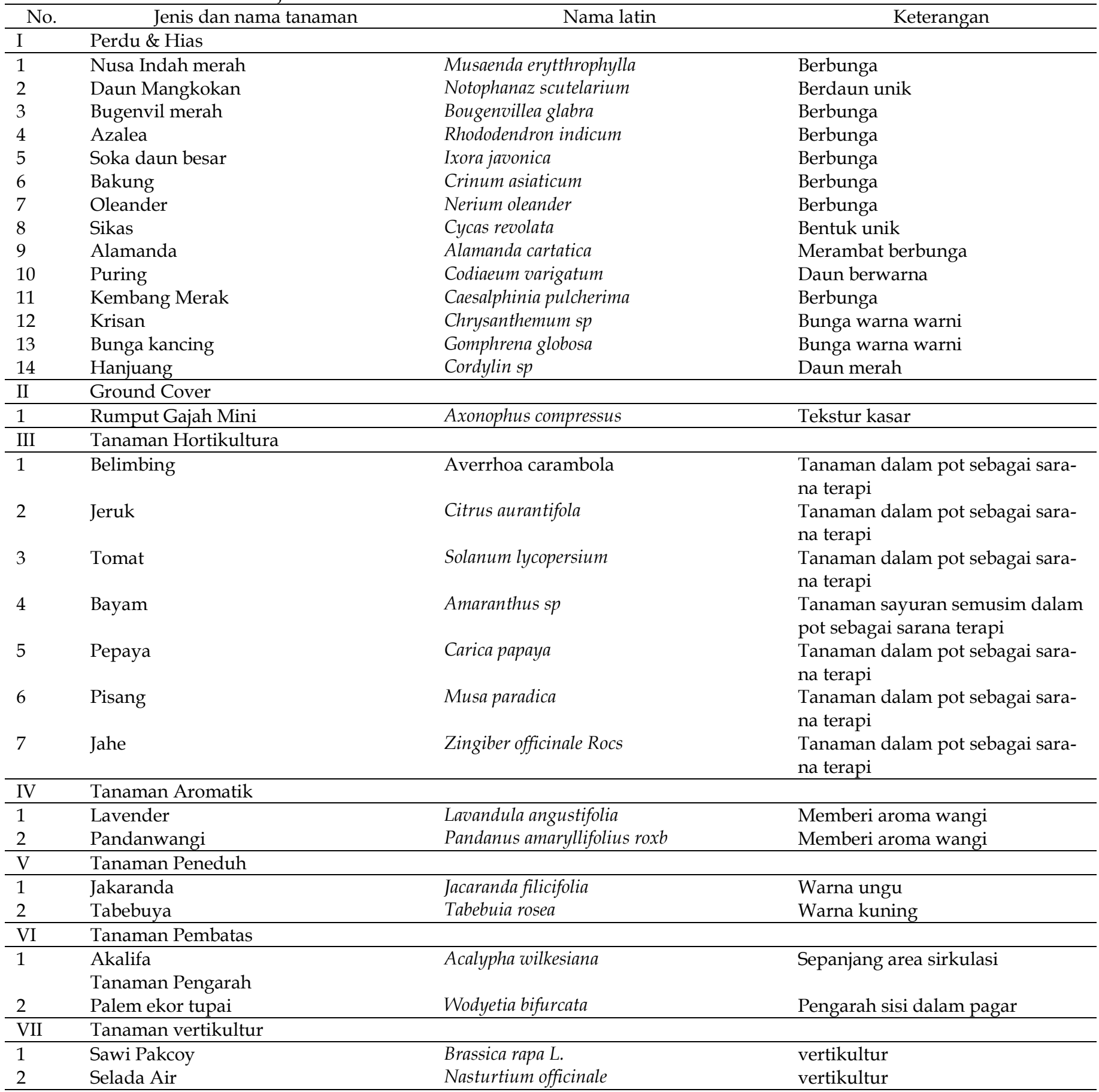




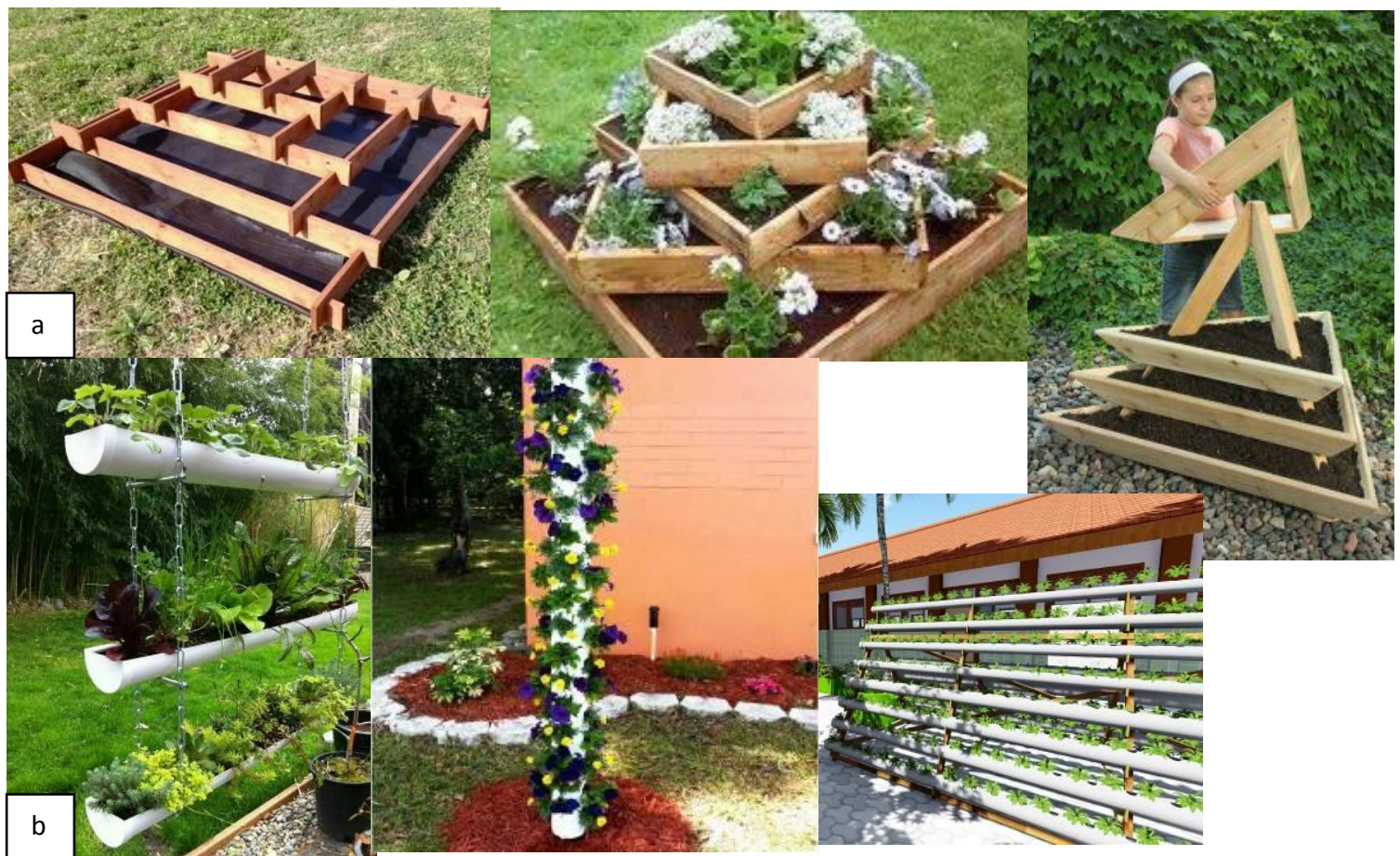

Gambar 10. Contoh konsep rancangan vegetasi (a) area bercocok tanam, (b) area vertikultur. Sumber : pinterest.com

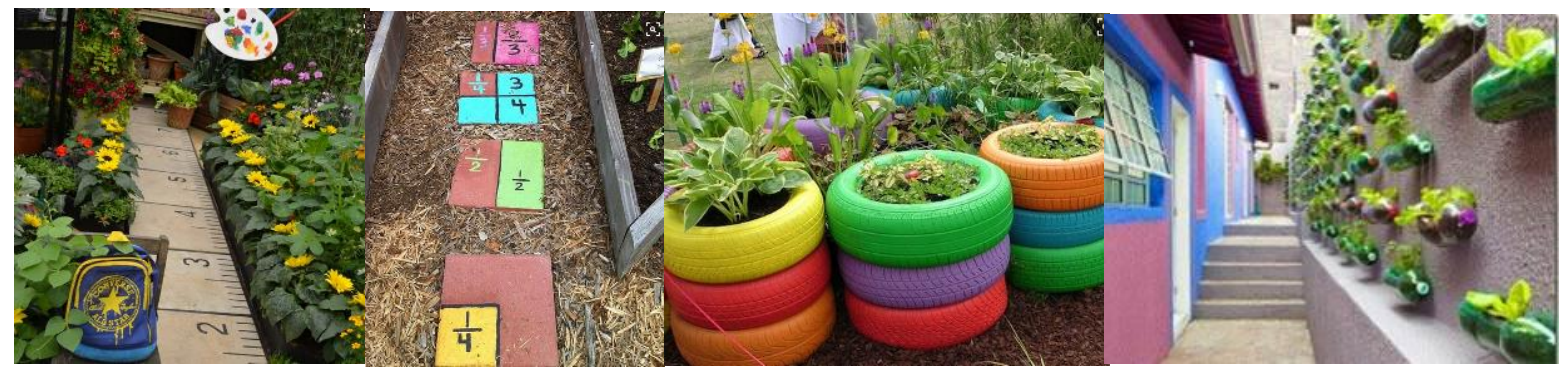

Gambar 11. Contoh konsep taman edukasi dalam bentuk pengenalan tanaman . Sumber : pinterest.com

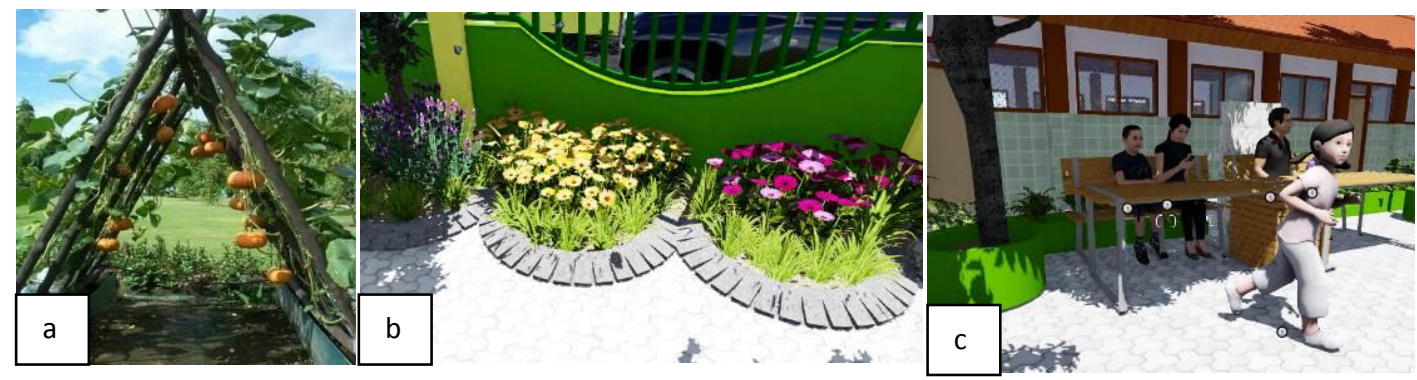

Gambar 12. Contoh konsep taman terapi. (a) terapi indera perasa dengan buah siap petik, (b) terapi indera penglihatan (visual) dengan warna-warni bunga, dan indera penciuman dengan aroma wangi bunga, (c) area tempat duduk yang teduh untuk menenangkan dan adanya area bermain aktif 


\section{SIMPULAN}

Peranan pekarangan sekolah sangat penting apabila dikaitkan dengan pembelajaran. Pada sekolah luar biasa, taman selain berfungsi pengisi lahan juga untuk terapi dan edukasi. Sebagai sarana terapi sensorik, siswa dapat meningkatkan ketajaman inderanya melalui visual, pendengaran, peraba, pengecap dan penciuman, sehingga tercapai titik fokus tertentu yang tidak menyebar. Sebagai sarana edukasi, siswa juga dilatih untuk mengenal lebih dekat tentang tanaman, merawat dan memanennya sehingga mendapatkan pengalaman langsung. Penggunaan material baik elemen keras maupun elemen lunak dipertimbangkan sisi keamanannya terhadap siswa sehingga tidak memberikan kecemasan ketika bermain. Konsep demikian bisa diterapkan di sekolah luar biasa lain dengan karakter pengguna yang sama.

\section{DAFTAR PUSTAKA}

Baskara, M. (2011). Prinsip Pengendalian Perancangan Taman Bermain Anak di Ruang Publik. Jurnal Lanskap Indonesia, 3 (1), pp. 27-34.

Direktorat Jenderal Penataan Ruang Departemen Pekerjaan Umum. (2008). Peraturan Menteri Pekerjaan Umum No : 05/PRT/M/2008 tentang Pedoman Penyediaan dan Pemanfaatan Ruang Terbuka Hijau di Kawasan Perkotaan.

Gold, S.M. (1980). Recreation Planning and Design. New York (US) : McGraw-Hill Book Companies, Inc.

Hakim, R. (2012). Komponen Perancangan Arsitektur Lansekap : Prinsip-Unsur dan Aplikasi Desain. Jakarta : PT. Bumi Aksara.

Haliimah, M., Asikin, D., dan Razziati H. (2014). Taman Sensori pada Ruang Luar Autism Center di Kota Batu.(Online).(http:/ / download.portalgaruda.org /article.php?article Diakses 13 April 2016)

Lauren, G.M. (2012). Desain Taman Lingkungan untuk Anak Usia Sekolah Dasar Di Cluster Callysta Permata, Perumahan Permata Bintaro, Tangerang Selatan.(online).http:/ / repository.ipb.ac.id/handl e/123456789/61159. diakses 21 April 2017.

Mandagi, A.U.G. (2013). Perancangan Taman Edukasi Lingkungan Untuk Anak-anak di Situ Cikaret, Kecamatan Cibinong, Kabupaten Bogor. (Online). http:/ / repository.ipb.ac.id/handle/123456789/66 082. diakses 21 April 2017.

Nasution. (2004). Metode Research (Penelitian Ilmiah). Jakarta : Bumi Aksara.

Ramadhani, W.S. (2016). Penerapan Pembelajaran Outdoor Learning Process (OLP) Melalui Pemanfaatan Taman Sekolah Sebagai Sumber Belajar Materi Klasifikasi Tumbuhan Untuk Meningkatkan Hasil Belajar Siswa SMP. Jurnal Pendidikan Sains, 4 (3), pp. 1-7.

Prabowo, B. A. (2015). Sensory Garden Sebagai Konsep Arsitektur Untuk Terapi Autisme. (Online). (http://blog.archadipa.com/index.php/2015/07/ 27/sensory-garden-sebagai-konsep-arsitekturuntuk-autisme/ diakses 13 April 2016)

Wahyuni, E. (2015). Sekolah Luar Biasa Autis Boyolali Berbasis Alam dengan Penekanan Taman Terapi. (Online).(http://eprints.ums.ac.id/38805/1/PUB LIKASI.pdf 